\title{
Significant caries index values and related factors in 5-6-year-old children in Istanbul, Turkey
}

N. Namal, ${ }^{1}$ A.A. Yüceokur ${ }^{1}$ and G. Can ${ }^{1}$

$$
\begin{aligned}
& \text { أهمية العوامل المتعلقة بقيم مَنْسَب تسوُّس الأسنان لدى الأطفال بعمر } 5 \text { - } 6 \text { سنوات في اسطنبول، تركيا }
\end{aligned}
$$

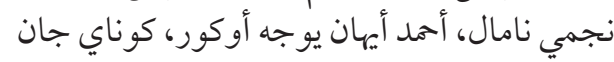

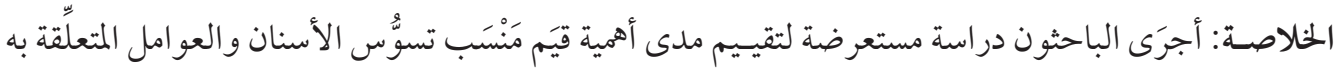

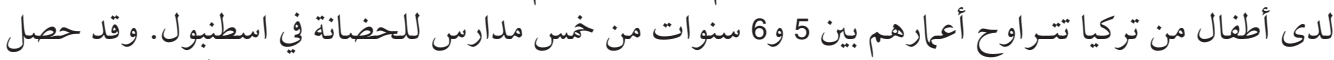

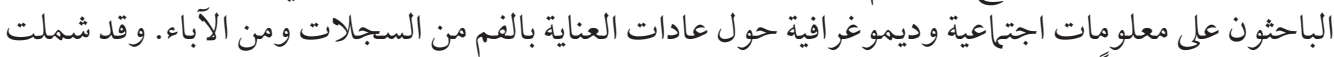

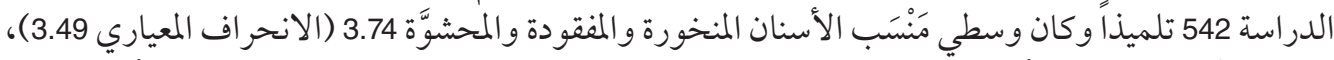

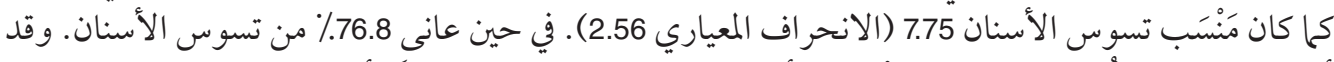

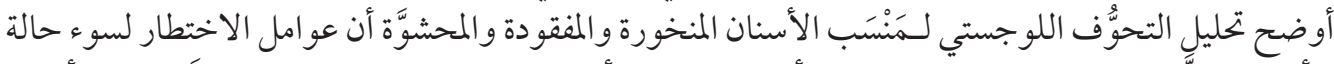

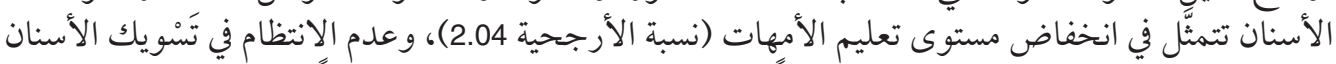

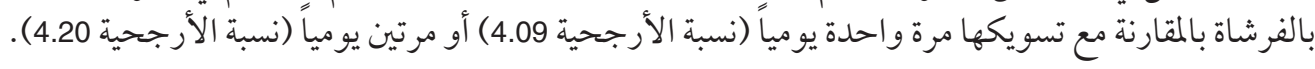

ABSTRACT To evaluate significant caries $(\mathrm{SiC})$ index values and related factors in Turkish children aged 5-6 years old, children from 5 nursery schools in Istanbul were included in a cross-sectional study. Sociodemographic information and data about oral care habits were obtained from the records and from parents. Of 542 students examined, the mean decayed/missing/filled primary teeth $(\mathrm{dmft})$ index was 3.74 (SD 3.49) and the SiC index was 7.75 (SD 2.56). About $76.8 \%$ of the children had experienced dental caries. Logistic regression analysis of the $\mathrm{SiC}$ index for dmft showed that risk factors for poor dental status were low mother's education (OR 2.04) and irregular toothbrushing versus once-a-day brushing (OR 4.09) or twice-a-day brushing (OR 4.20).

Valeurs d'indice significatif de caries et facteurs associés chez les enfants âgés de 5 à 6 ans à Istanbul (Turquie)

RÉSUMÉ Afin d'évaluer les valeurs d'indice significatif de caries (SiC, pour Significant Caries index) et les facteurs associés chez les enfants turcs âgés de 5 à 6 ans, une étude transversale a été réalisée sur les enfants de cinq écoles maternelles d'Istanbul. Les informations sociodémographiques et les données sur les habitudes d'hygiène bucco-dentaire provenaient des dossiers dentaires et des parents. Sur 542 écoliers examinés, l'indice CAO moyen (dent de lait cariée, absente ou obturée) était de 3,74 (E.T. 3,49) et l'indice SiC de 7,75 (E.T. 2,56). Environ 76,8 \% des enfants avaient eu des caries dentaires. L'analyse de régression logistique de l'indice $\mathrm{SiC}$ par rapport à l'indice $\mathrm{CAO}$ a montré que les facteurs de risque associés à une mauvaise santé bucco-dentaire étaient un faible niveau d'instruction de la mère $(\mathrm{OR} 2,04)$ et un brossage des dents irrégulier, comparé à un brossage une fois par jour (OR 4,09 ) ou deux fois par jour (OR 4,20).

\footnotetext{
${ }^{1}$ Department of Public Health, Cerrahpasa Medical Faculty, University of Istanbul, Istanbul, Turkey (Correspondence to N. Namal: necminamal@yahoo.com).

Received: 20/03/06; accepted: 22/08/06
}

المجلة الصحية لشرق المتوسط، منظمة الصحة العالمية، المجلد الخامس عشر، العدد (، 9 +. 


\section{Introduction}

A detailed analysis of the caries prevalence in many countries has often shown a skewed distribution of the disease: a group of 12-year-olds may have high or very high decayed/missing/filled teeth (DMFT) values, while the rest of the age group shows low DMFT or are totally caries-free [1-3]. Obviously, expressing caries prevalence as the mean DMFT value does not correctly reflect the skewed distribution, leaving high caries groups undiscovered in the population. In order not to lose the positive momentum gained from various oral health programmes around the world, and to target the still caries-susceptible individuals in the population, a new index, the significant caries $(\mathrm{SiC})$ index, was introduced in the year 2000 to call attention to those children with the highest scores in each population [4]. The $\mathrm{SiC}$ index is calculated by taking the mean DMFT of the one-third of the individuals having the highest of DMFT values in a given population $[2,4]$. The use of the $\mathrm{SiC}$ index may solve the problem related to skewed caries distribution [5]. In addition, a new goal was proposed: the $\mathrm{SiC}$ index should be less than 3 DMFT among 12-year-olds by the year 2015 [2].

Although the range of $\mathrm{SiC}$ index values for 12-year-olds is wide [6], it is narrower for 5-6-year-olds [7-10]. According to World Health Organization (WHO) data, $\mathrm{SiC}$ values were 5.6 DMFT in Austria, 4.7 in Australia, 7.3-7.7 in the Czech Republic, 8.1 in Trinidad and 5.3-6.8 in Germany [7-10]. To our knowledge there are no data available about the $\mathrm{SiC}$ values for primary and permanent teeth in Turkish children. According to a previous study in 1990, the average $\mathrm{dmft}$ index in 6-year-olds was 4.4 [11].

The objective of this study therefore was to present the first $\mathrm{SiC}$ data for 5-6-yearolds in Turkey to contribute to the interna- tional data repository as well as to research the factors concerning oral care habits that may have an effect on these $\mathrm{SiC}$ values.

\section{Methods}

This cross-sectional study was conducted on a randomly selected sample of children in the Bagcilar and Gaziosmanpasa districts of Istanbul. These districts were selected as their sociodemographic characteristics are very close to the average values for Istanbul [12]. The study was conducted in 5 nursery schools selected by random sampling from the nursery schools reporting to the Social Services and Child Protection Agency and Gaziosmanpasa municipality during the period June to December 2002. During the study period, all students attending the 5 schools were included in the study. Schools were revisited to recruit absent students and ensure that all the students participated in the study. No student refused to participate in the study. The survey was performed on 542 nursery-school students: 295 who paid school fees and 247 who were enrolled free of charge.

Oral examinations were carried out in classrooms with the help of a plain mirror and the ballpoint probe under daylight or, where necessary, using a portable source of light. The same examiner performed all examinations. No radiographs were taken. Ethical approval for this study was obtained from the Ethics Committee of the Cerrahpasa Medical School of the University of Istanbul. The number of carious defects, fillings and missing primary teeth were recorded on examination forms in accordance with $\mathrm{WHO}$ criteria and the $\mathrm{dmft}$ scores were calculated according to WHO guidelines [13]. Individuals were grouped into tertiles according to their dmft values. The $\mathrm{SiC}$ index was calculated as the mean dmft of the

المجلة الصحية لشرق المتوسط، منظمة الصحة العالمية، المجلد الخامس عشر، العدد (،9.ب. 
one-third of the population with the highest caries scores $[2,4]$.

Data on age, sex and number of siblings were obtained from the existing school files of the students. To collect data on mother's level of education, family income and oral hygiene habits, parents were sent questionnaires to complete. This method was used as young children may not be able to give correct answers about toothbrushing habits. Mother's level of education was classified as $0-7$ years of education or $8+$ years. Children were classified according to the number of times a day they brushed their teeth: twice, once or irregularly (if they brushed their teeth less than once a day). For family income evaluation, the classifications of the State Statistics Institute were used [14]. Monthly family income in Turkish lira (TL) was classified as low [TL 250-500 (US\$ 150-300)] or high [> TL 500 (> US\$ 300)].

In addition to descriptive statistics, both univariate and multivariate analyses were done. Univariate analyses and logistic regression analyses were performed for all variables. Logistic regression using SPSS software was done to identify significant risk factors for dmft. In addition to $P$-values, the chi-squared, odds ratio (OR) and its $95 \%$ confidence interval (CI) were computed.

\section{Results}

Of the children participating in the study 261 were 5 years old and 281 were 6 years old; $312(57.6 \%)$ were boys and $230(42.4 \%)$ were girls. More than half of the children (58.5\%) had no siblings. Approximately one-third of the mothers $(28.4 \%)$ had received schooling for 8 years and more. More than half of the families $(54.2 \%)$ had a high family income. The figures for monthly income as stated by the families were likely to be correct as nearly all the families who declared a high monthly income were the families of students who attended private schools.

The mean dmft of the children was 3.74 [standard deviation (SD) 3.49]. The SiC index value was 7.75 (SD 2.56). About 76.8\% of children had experienced dental caries. According to parents' reports, $67.2 \%$ of the children brushed their teeth once a day or more. The cut-off for the $\mathrm{SiC}$ index (i.e. the one-third of the group with the highest caries scores) was $5+\mathrm{dmft}$. Children within the $\mathrm{SiC}$ index range (i.e. $5+\mathrm{dmft}$ ) were compared with children outside the $\mathrm{SiC}$ index (i.e. dmft < 5) (Table 1).

No significant difference was found in the percentage of children above and below the $\mathrm{SiC}$ cut-off value by age, sex or number of siblings. More children from low-income families had dmft $5+$ than the children from high-income families and this difference was significant $\left(\chi^{2}=2.72 ; P<0.05\right)$. When the effect of the education level of the mothers was evaluated, a significant difference was found; mothers of children with dmft $5+$ had lower education level $\left(\chi^{2}=10.87 ; P\right.$ $<0.05)$. More children who brushed their teeth less than once a day had dmft $5+$ than children who brushed once or more a day and this difference was significant $\left(\chi^{2}=\right.$ 8.89; $P<0.05$ ) (Table 1).

The outcome of the conditional logistic regression model for $\mathrm{SiC}$ value is presented in Table 2. Children of mothers with $0-7$ years of education were 2.04 times more likely have dmft $5+$ than children of mothers with $8+$ years of education $(\mathrm{OR}=2.04$; 95\% CI: $1.23-3.38 ; P=0.006)$. Children who brushed their teeth irregularly were 4.09 times more likely to have $\mathrm{dmft} 5+$ than children who brushed their teeth once a day $(\mathrm{OR}=4.09 ; 95 \% \mathrm{CI}: 1.53-10.93 ; P=$ $0.005)$ and 4.20 times more likely than children who brushed their teeth twice or more a day $(\mathrm{OR}=4.20 ; 95 \% \mathrm{CI}: 1.53-11.50 ; P=$ 


\begin{tabular}{|c|c|c|c|c|c|}
\hline \multirow[t]{2}{*}{ Variable } & \multicolumn{2}{|c|}{ dmft 5+ } & \multicolumn{2}{|c|}{$\mathrm{dmft}<5$} & \multirow[t]{2}{*}{$\chi^{2}$ value } \\
\hline & No. & $\%$ & No. & $\%$ & \\
\hline \multicolumn{6}{|l|}{ Age (years) } \\
\hline 5 & 92 & 35.2 & 169 & 64.8 & 0.007 \\
\hline 6 & 100 & 35.6 & 181 & 64.4 & \\
\hline \multicolumn{6}{|l|}{ Sex } \\
\hline Male & 117 & 37.5 & 195 & 62.5 & 1.39 \\
\hline Female & 75 & 32.6 & 155 & 67.4 & \\
\hline \multicolumn{6}{|l|}{ Family income } \\
\hline Low & 97 & 39.1 & 151 & 60.9 & $2.72^{*}$ \\
\hline High & 95 & 32.3 & 99 & 67.7 & \\
\hline \multicolumn{6}{|c|}{ Mother's education (years) } \\
\hline $0-7$ & 154 & 39.7 & 234 & 60.3 & $10.87^{*}$ \\
\hline $8+$ & 38 & 24.7 & 116 & 75.3 & \\
\hline \multicolumn{6}{|l|}{ No. of siblings } \\
\hline 0 & 101 & 31.9 & 216 & 68.1 & 4.27 \\
\hline 1 & 78 & 40.2 & 116 & 59.8 & \\
\hline $2+$ & 13 & 41.9 & 18 & 58.1 & \\
\hline \multicolumn{6}{|l|}{ Toothbrushing } \\
\hline Irregularly & 67 & 37.6 & 111 & 62.4 & $8.89^{*}$ \\
\hline Once a day & 131 & 38.9 & 205 & 61.1 & \\
\hline Twice a day or more & 3 & 10.7 & 25 & 89.3 & \\
\hline
\end{tabular}

${ }^{*} P<0.05$.

$0.005)$. No other covariate was significantly associated with the outcome.

\section{Discussion}

The mean dmft value (3.74) in this study of 5-6-year-olds in 2 districts of Istanbul is close to the average value for both Istanbul and Turkey [12]. No study is available about the association between the 2 indicators, $\mathrm{SiC}$ values and dmft, in Turkish children. Furthermore, we could not find any study in the international literature about the factors affecting the $\mathrm{SiC}$ values of 5-6-year-olds. Our survey can therefore help in designing future prospective studies.
The prevalence of 5-6-year-old children with dental caries was $76.8 \%$. This figure is worse than in Austria, a developed country (49.0\%) and in Mexico (61.6\%) and Nicaragua $(72.6 \%)$, which are developing countries $[9,15,16]$. Compared with the target of $50 \%$ individuals with no dental caries for 5-6-year-old children proposed by WHO in 2000 [17], the values for 5-6-year-old children in Istanbul are very poor.

The mean dmft value found in our study (3.74) is better than that of $4.4 \mathrm{dmft}$ reported previously for 6-year-olds in Turkey [11]. This shows that there was some improvement in the oral health of 6-year-old children in Istanbul between 1990 and 2002. Our 
Table 2 Logistic regression analysis for significant caries index (SiC) values

\begin{tabular}{|c|c|c|c|c|c|c|}
\hline Variable & B & SE & Wald $\chi^{2}$ & df & $P$-value & OR $(95 \% \mathrm{Cl})$ \\
\hline \multicolumn{7}{|l|}{ Age (years) } \\
\hline \multicolumn{7}{|l|}{5} \\
\hline 6 & 0.266 & 0.270 & 0.970 & 1 & 0.325 & $1.30(0.77-2.21)$ \\
\hline \multicolumn{7}{|l|}{ Sex } \\
\hline \multicolumn{7}{|l|}{ Female } \\
\hline Male & -0.211 & 0.189 & 1.246 & 1 & 0.264 & $0.81(0.56-1.17)$ \\
\hline \multicolumn{7}{|l|}{ Family income } \\
\hline \multicolumn{7}{|l|}{ High } \\
\hline Low & 0.134 & 0.308 & 0.189 & 1 & 0.663 & $1.14(0.63-2.09)$ \\
\hline \multicolumn{7}{|c|}{ Mother's education (years) } \\
\hline \multicolumn{7}{|l|}{$8+$} \\
\hline $0-7$ & 0.712 & 0.258 & 7.638 & 1 & 0.006 & $2.04(1.23-3.38)$ \\
\hline \multicolumn{7}{|l|}{ No. of siblings } \\
\hline 0 & & & 2.415 & 2 & 0.299 & \\
\hline 1 & -0.190 & 0.406 & 0.220 & 1 & 0.639 & $0.83(0.37-1.83)$ \\
\hline $2+$ & 0.120 & 0.405 & 0.088 & 1 & 0.767 & $1.13(0.51-2.50)$ \\
\hline \multicolumn{7}{|l|}{ Toothbrushing } \\
\hline Irregularly & & & 8.149 & 2 & 0.017 & \\
\hline Once a day & 1.409 & 0.501 & 7.906 & 1 & 0.005 & $4.09(1.53-10.93)$ \\
\hline Twice or more & 1.434 & 0.515 & 7.764 & 1 & 0.005 & $4.20(1.53-11.50)$ \\
\hline Constant & -2.517 & 0.690 & 13.309 & 1 & 0.000 & 0.08 \\
\hline
\end{tabular}

$B=$ coefficient $B ; S E=$ standard error $d f=$ degrees of freedom; $O R=$ odds ratio; $C I=$ confidence interval.

value is close to the value in the Czech Republic for 5-year-olds (3.3-3.7) and Uganda for 6-year-olds (3.1-3.3) [7,18] and matches the value from Trinidad for 6-year-olds (3.7) [10]. It is higher than the mean dmft values of Austria (2.1) and Australia for 6-yearolds (1.65) and Germany for 6-7-year-olds $(1.98-2.8)[8,9,19]$. It is lower than the $\mathrm{dmft}$ values of Saudi Arabia (4.8) and Abu Dhabi for 6-year-olds (8.4) [20,21]

In this study, the $\mathrm{SiC}$ value for 5-6-yearold children was 7.75. This is higher than the $\mathrm{SiC}$ values for Austria (5.6) and Australia (4.7) for 6-year-olds, the Czech Republic for 5-year-olds (7.3-7.7) and Germany for 6-7-year-olds (5.3-6.8) [7-10,19]. However, it is lower than the value for Trinidad for 6-year-olds (8.1). The WHO SiC index target for 12-year-olds in 2015 is 3 DMFT [2]. However, there is no WHO target for the $\mathrm{SiC}$ levels for dmft of primary teeth of 5-6-year-olds. Since there is no such target, we could not compare our study and other studies with a standard value.

To our knowledge there has been no study about the factors affecting the $\mathrm{SiC}$ value of both 5-6-year-olds and 12-yearolds. Therefore we need to use the values of dental caries and dmft/DMFT in comparisons. It has been shown before that dmft values are affected by age [22], sex [23], regular toothbrushing [24] and family income [9]. These studies mostly examined one or more factors in bivariate analyses of risk indicators. In our study, several risk indicators for the $\mathrm{SiC}$ value of $\mathrm{dmft}$ 
were taken into consideration - sex, family income, mother's education, number of siblings and toothbrushing. Our results showed that mother's education and toothbrushing were associated with the $\mathrm{SiC}$ value of dmft. Higher levels of mother's education had a positive impact on the dental health of their children. Children of mothers who had 0-7 years of education had $\mathrm{SiC}$ values twice as high as those of the children of mothers who were educated for 8 years or more. Greater frequency of toothbrushing also had a positive impact on dental health. Children who brushed their teeth irregularly had 4.09 and 4.20 times higher $\mathrm{SiC}$ values respectively than those brushing their teeth once or twice or more per day. These results agree with those of other studies that showed that higher education level of mothers and frequency of toothbrushing have a positive impact on dental caries $[9,10,17]$.

In the short term, health planners may not be able raise the educational level of mothers. On the other hand, there is no doubt that the dental health of these children can be positively influenced if children in school, starting with nursery school, are taught to make it a habit to brush their teeth regularly, properly and effectively. A target of WHO for the year 2015 is the placement of health improvement programmes in $95 \%$ of all schools and $50 \%$ of all nursery schools [25]. It is clear that programmes in line with such targets are a requirement for the children of Turkey.

\section{References}

1. World Health Organization oral health country/area profile programme [website] (http://www.whocollab.od.mah.se/index. html, accessed 20 March 2008).

2. Nishi $\mathrm{M}$ et al. Caries experience of some countries and areas expressed by the Significant Caries Index. Community dentistry and oral epidemiology, 2002, 30(4):296-301.

3. Burt BA. Prevention policies in the light of the changed distribution of dental caries. Acta odontologica Scandinavica, 1998, 56(3):179-86.

4. Bratthall D. Introducing the Significant Caries Index together with a proposal for a new global oral health goal for 12-yearolds. International dental journal, 2000, 50(6):378-84.

5. Campus $\mathrm{G}$ et al. The "Significant Caries Index" (SiC): a critical approach. Oral health and preventive dentistry, 2003, 1(3):171-8.

6. Marthaler T, Menghini G, Steiner M. Use of the Significant Caries Index in quantifying the changes in caries in Switzerland from 1964 to 2000. Community dentistry and oral epidemiology, 2005, 33(3):159-66.

7. Lencovà $E$ et al. Caries of upper deciduous incisors in 5-year-olds: an attempt at epidemiological definition of early childhood caries. Caries research, 2002, 36(3):204.

8. Momeni A, Pieper K, Stoll R. Rückgang der karies-prävalenz bei 6- bis 7-jährigen in Hessen in den Jahren 1994 bis 2000 [Decline in caries prevalence of 6- to 7 -year-olds in Hesse in the years 1994 to 2000]. Oralprophylaxe, 2002, 24(3):99102.

9. StadtlerPetal. Prevalence of caries in 6-yearold Austrian children. Oral health and preventive dentistry, 2003, 1(3):179-83.

10. Adawakun AA et al. Caries status of children in eastern Trinidad, West Indies. Oral health and preventive dentistry, 2005, 3(4):249-61.

11. Saydam G et al. Oral health in Turkey: situation analysis. Istanbul, Turkey, Min- 
istry of Health, and Copenhagen, World Health Organization Regional Office for Europe, 1990.

12. Statistical yearbook of Turkey. Ankara, State Institute of Statistics, Prime Ministry Republic of Turkey, 2001.

13. Oral health surveys: basic methods, 4th ed. Geneva, World Health Organization, 1997.

14. Turkish Statistical Institute. Republic of Turkey Prime Ministry [website] (http:// www.die.gov.tr/TURKISH/SONIST/ HHGELTUK/0711103.htm) [in Turkish].

15. Casanova-Rosado AJ et al. Dental caries and associated factors in Mexican schoolchildren aged 6-13 years. Acta odontologica Scandinavica, 2005, 63(4):245-51.

16. Herrera Mdel S et al. Prevalencia de caries dental en escolares de 6-12 anos de edad de Leon, Nicaragua [Prevalence of dental caries in 6-12-year-old school children in Leon, Nicaragua]. Gaceta sanitaria, 2005, 19(4):302-6.

17. Aggeryd T. Goals for oral health in the year 2000. Cooperation between WHO, FDI and the national dental associations. International dental journal, 1983, 33(1):55-9.

18. Kiwanuka SN et al. Dental caries experience and its relationship to social and behavioural factors among 3-5-year-old children in Uganda. International journal of paediatric dentistry, 2004, 14(5):336-46.

19. Armfield JM et al. Dental health differences between boys and girls: the Child
Dental Health Study, Australia 2000. AIHW cat. No. DEN 131. Canberra, Australian Institute of Health and Welfare (Dental Statistics and Research Series No: 31).

20. Al-Malik Ml et al. Prevalence and patterns of caries, rampant caries and oral health in two- to five-year-old children in Saudi Arabia. Journal of dentistry for children, 2003, 70(3):235-42.

21. Al-Hosani E, Rugg-Gunn A. Combination of low parental educational attainment and high parental income related to high caries experience in pre-school children in Abu-Dhabi. Community dentistry and oral epidemiology, 1998, 26(1):31-6.

22. Eronat N, Koparal E. Dental caries prevalence, dietary habits, tooth-brushing, and mother's education in 500 urban Turkish children. Journal of Marmara University Dental Faculty, 1997, 2(4):599-604.

23. Bolin AK et al. Children's dental health in Europe. Sociodemographic factors associated with dental caries in groups of 5- and 12-year-old children from eight EU countries. Swedish dental journal, 1997, 21(1-2):25-40.

24. Verrips $\mathrm{GH}$ et al. Ethnicity and maternal education as risk indicators for dental caries and the role of dental behaviour. Community dentistry and oral epidemiology, 1993, 21(4):209-14.

25. Health 21. The health for all policy framework for the WHO European Region. Copenhagen, World Health Organization Regional Office for Europe, 1999 (European Health for All Series, No. 6). 